\title{
Persistence of geographic memories in adults
}

\author{
WILLIAM W. BEATTY and MARGARET SPANGENBERGER \\ North Dakota State University, Fargo, North Dakota
}

\begin{abstract}
Beatty (1985) observed that knowledge of geographical features of the region in which people were born and raised was as accurate as their knowledge of the geography of the region in which they currently resided. To test the idea that the apparent preservation of geographic knowledge of the region of former residence is periodically refreshed by visits to that region, we compared geographic knowledge of Northern regions of the U.S. by two groups of residents of a retirement complex in Florida. Some of the subjects had migrated from the North an average of 22 years earlier and had become year-round Florida residents. Others returned to a Northern region annually. The two groups displayed nearly identical accuracy on tests of knowledge of the geography of the Northern regions, suggesting that some forms of geographic knowledge are so durable that little or no relearning is required for their maintenance.
\end{abstract}

Although the acquisition of accurate spatial memories has been intensively investigated during the past two decades, the retention of spatial knowledge over extended periods has received little attention. An exception is the work of Bahrick (1983), who studied the acquisition and retention of knowledge of the spatial features of a small city and a university campus by students and alumni. On all measures of spatial knowledge, performance declined with time since graduation. The rate of loss varied markedly from one measure to another so that after 20 years retention varied from less than $10 \%$ to about $70 \%$ of the estimated proficiency at graduation. Retention was better for alumni who had returned to campus than for those who had never done so.

In contrast to Bahrick's (1983) results, which reveal marked forgetting of spatial information, are the findings of Beatty (1985), who studied the ability of older subjects to locate places on outline maps of the region in which they were born and raised (Region 1) and the region in which they currently lived (California-Nevada). Despite the fact that these subjects had moved away from Region 1 an average of 30 years previously and had never again resided there, they located places on the Region 1 map just as accurately as on the CA-NV map $(M \mathrm{~s}=69.4 \%$ and $72.7 \%$ correct, respectively).

Although this observation may support the view that geographic knowledge is so highly overlearned that it is relatively immune to the sort of loss that affects most other memories, another interpretation is plausible. Specifically, it may be argued that accurate memory for the geography of regions in which one has formerly lived is periodically refreshed by visits to these regions.

The present experiment was performed to evaluate the importance of returning to a region of former residence in maintaining accurate memory for the geography of that region. To test the significance of this factor, we com-

Please address correspondence to William W. Beatty, Department of Psychology, North Dakota State University, Fargo, ND 58105. pared performance of two groups of winter residents of a retirement complex in Florida. One group had moved away from the North more than 20 years earlier and established permanent residence in Florida. The other group (the "snowbirds") spent their winters in Florida and their summers in some Northern region. If maintaining accurate geographical memory requires periodic relearning that occurs incidentally during the course of return visits to an area of former residence, then it would be predicted that the snowbirds would be able to locate places on the maps of the Northern regions more accurately than would the permanent Florida residents.

\section{METHOD}

\section{Subjects}

The subjects were 13 permanent residents ( 9 males, 4 females) of a retirement complex in Dunedin, Florida, who had moved away from regions in the Northeast or North Central parts of the U.S. an average of 21.9 years earlier, and 14 winter residents ( 7 males, 7 females) of the same retirement complex who returned to the North every summer (the snowbirds). The permanent residents of Florida averaged 71.2 years of age (range: 44-92) and 13.2 years of education (range: 8-16, whereas the snowbirds averaged 69.5 years of age (range: $57-82$ ) and 13.3 years of education (range: 8-19). The distribution of Northern regions from which the permanent residents had migrated and to which the snowbirds returned annually was quite similar as well.

\section{Procedure}

An abbreviated form of the standard version of the Fargo Map Test (FMT; Beatty, in press) was used, which the subjects completed on their own. They filled out the residential history; indicated whether or not they returned to the North each summer; and completed the U.S. map, the Florida map, and the map of the relevant Northern region. Subjects were asked not to look at a map or to collaborate with another person. The tests were scored by an experienced rater, as described by Beatty (in press).

\section{RESULTS AND DISCUSSION}

As shown in Table 1, average performance by the permanent Florida residents and the snowbirds was quite similar on all maps, and there were no group differences 
Table 1

Mean Percent Correct (\%) on Map Tests

\begin{tabular}{lccccc}
\hline & \multicolumn{3}{c}{$\begin{array}{c}\text { Permanent Florida } \\
\text { Residents }\end{array}$} & & \multicolumn{2}{c}{ Snowbirds } \\
\cline { 2 - 3 } Map & $\%$ & SD & & SD \\
\hline U.S. & 83.9 & 21.4 & & 89.5 & 12.6 \\
Florida & 66.2 & 23.5 & & 70.1 & 23.7 \\
Northern Region & 65.3 & 23.7 & & 65.2 & 25.2 \\
\hline
\end{tabular}

$(F \mathrm{~s}<1)$. Of particular importance was the nearly identical performance by the two groups on the maps of the Northern regions. This observation strongly suggests that little, if any, direct relearning is required to maintain accurate geographical memories of the sort tested in the present study.

As Bahrick's (1983) findings show, these conclusions do not hold for all forms of geographical memory. In particular, the highly specific information about local features measured in Bahrick's tests may simply be more vulnerable to loss, unless refreshed, than the relatively gross geographic knowledge tapped by the FMT. Alternatively, the geographic memories measured by the FMT may be renewed by incidental exposure to media sources (e.g., weather reports).
Regardless of which view ultimately proves to be correct, the durability of geographic knowledge in the elderly makes assessment of such knowledge potentially attractive for neuropsychological studies, especially since the FMT has been shown to be sensitive to the remote memory deficits in amnesia and in the early stages of dementia (Beatty, 1985; Beatty, MacInnes, Porphyris, Tröster, \& Cermak, in press).

\section{REFERENCES}

BAHRICK, H. P. (1983). The cognitive map of a city: Fifty years of learning and memory. Psychology of Learning \& Memory, 17, 125-163. BeATTY, W. W. (1985). Assessing remote memory for space: The Fargo Map Test. Journal of Experimental \& Clinical Neuropsychology, 7, 640. (Abstract)

BeatTy, W. W. (in press). The Fargo Map Test: A standardized method for assessing remote memory for visuospatial information. Journal of Clinical Psychology.

Beatty, W. W., Macinnes, W. D., Porphyris, H. S., Tröster, A. I., \& Cermak, L. S. (in press). Topographical memory following right temporal lobectomy and in amnesia. Brain \& Cognition.

(Manuscript received for publication July 20, 1987.) 